\title{
Risk Management implementation and presenting the applicable methodology for its implementation in construction projects
}

\author{
Mukhammet Fakhratov ${ }^{1, *}$, Vitali Chulkov ${ }^{1}$, Marat Kuzhin ${ }^{1}$, and Mohammad Sharif Akbari ${ }^{1}$ \\ ${ }^{1}$ Russia Moscow State University of Civil Engineering (National Research University), 26, \\ Yaroslavskoye Shosse, 129337, Moscow, Russia
}

\begin{abstract}
The main task of the project manager is risk management. However, this task can be very complicated and inefficient if risk management is not considered from the beginning of the project. An effective risk management approach requires a systematic and appropriate approach, knowledge and experience. Studies of many projects have shown that both the owner and the contractor do not regularly implement risk management practices, which can have negative consequences on project performance. Because of the above-mentioned issues in this study, it is attempted to first evaluate the concepts of project risk management based on different and valid standards, to evaluate risk management in construction projects. Then, an attempt has been made to present an implementation approach for implementing six stages of risk management in projects. For this purpose, based on the experiences of the project "Lala Residential Complex" in Kabul, as a case study, the experimental application of the proposed method in this study, step by step, along with forms designed for follow-up and Implementation of process steps have been evaluated and evaluated in accordance with the PMBOK standard by the Project Management Institute (PMI) to ensure that it is moving toward achieving project economic risk management goals.
\end{abstract}

\section{Introduction}

Although various definitions of risk management and its stages provided so far, all three main areas of identification, evaluation, and control observed. In some cases, risk control is mistakenly referred to as risk management. Besides, in some systems, the revision section is also considered the last step. In risk management systems developed for highly uncertain environments, especially concerning land and engineering activities, there is a strong emphasis on risk identification and control processes [1].

It should be noted, that in the primary design phase, a qualitative risk assessment, based on identifying the potential risk in the construction work expected in each particular project, as well as covering all the types of risks considered in the risk policy formulated by the employer, must be follow-up properly [2].

\footnotetext{
*Corresponding author: fahratov@mail.ru
} 
Implementing a qualitative risk assessment approach initially has the essential advantage of preventing time and cost savings in later stages of risk assessment. In these conditions, risk studies can be focused on serious risks. On the other hand, one can do this by first qualitatively or semi-quantitatively assessing the severity of the accident and then classifying cases that are inconsistent with the accepted criteria of the employer. A little more based on frequency. In general, the purpose of the initial risk classification is to provide a framework for quantitative risk assessment and cost. In small and large-scale projects, technical complexity plays a major role in the risks, but in many cases is not considered to be the main reason for the increase in costs and time [3].

However, any construction project, including an infrastructure project, must meet its defined goals and functions in the first phase, in the next phase, the design, and the construction phase must be safe and economical. In this case, avoiding any risk regarded as good engineering and providing optimal conditions will be evaluated. In the meantime, it is necessary to involve the cost of the project completed without risk. On the other hand, risk avoidance is also opposed to innovation, so the design department accepts some of the risks and follows the design and execution of projects according to them [4].

\subsection{Risk management process}

Risk management is a systematic process of identifying, analyzing, and responding to project risks in order to maximize positive outcomes and events and reduce the likelihood or impact of adverse consequences on project goals that can affect time, cost, quality, and efficiency. Moreover, it affects the performance of the project. Risk management is a step towards project effectiveness, efficiency and of course, becoming more scientific, identifying uncertainties before they occur and turning them into a crisis and creating a balance between threats and opportunities (Considering the organization risk capacity/project and nature of the risk) [5-6].

In risk management, questions such as how to identify project risks, how to rate and prioritize project risks, how to consider the uncertainties, how to respond to the risks, and like that, answered, Is requires detailed project analysis. By identifying uncertainties and managing them, the project is primarily economic/non-economic, identifying the uncertainties and opportunities of each uncertainty, and secondly identifying appropriate strategies for controlling threats and enhancing opportunities. Identifying and finally choosing the right strategy (avoidance/exploitation, reduction/promotion, transfer/partnership, for each threat or opportunity) can be a great step towards achieving the project goals.

The risk management process is how project risks (the area of project outputs, resources, etc.), are formally identified, rated and managed during project execution. This process involves performing activities designed to reduce the probability of an event and the severity of the impact of each risk. The risk management process as defined by ISO10006 has the following steps [7-8]:

- $\quad$ Risk identification

- $\quad$ Risk assessment

- $\quad$ Risk accountability

- $\quad$ Risk control

Besides, the US Project Management Institute (PMI) has introduced a six-step approach to risk management from a more comprehensive perspective. In these steps, threats and opportunities are reviewed in parallel, and according to the steps proposed, a suitable plan is developed for each of them so that future project uncertainties can be tracked and controlled as far as possible. Following is a systematic introduction to the systematic risk management process $[9,10]$. 


\subsection{The role of coordinating project pillars to reduce risk}

In any construction project, the legal definitions of the tasks of the three essential pillars of each project, employer, consultant, and contractor are well defined. However, with a brief look at some of the country's development plans, it is easy to see the unsuccessful implementation of the project which didn't apply these definitions. The performance status of such projects indicates that the two factors of minimizing costs and optimizing the project schedule were less than desirable. Therefore, it is necessary to identify the main tasks of the components of a project, to coordinate the execution structure of the project, and ultimately to achieve the two essential factors mentioned above. In summary, you can access this important in the following three options:

Considering the technical and professional skills of the pillars of the project as the main criterion in selecting the responsibilities for each pillar.

Complete attention and commitment to the task description and control system during execution.

Creating a dynamic work environment with national and religious sentiment among all project stakeholders is generally the first pillar of any development project employer [1113].

The employer is fully responsible for the project during its implementation and operation. The most important duties of an employer can be to forecast the necessary funds and to select a project manager. Correct selection of the project executor, who within the framework of the existing rules, is responsible for selecting the consultant and contractor, is one of the most important factors in the success of any development project. There is no doubt that any successful national project such as mass projects owes its full respect to the principles under consideration and ultimately to the technical coordination between the pillars of the project, which undoubtedly require the role of the macro-planning authorities in establishing such an organization.

The employer plays a leading and decisive role in the design, engineering, and technical study planning as part of the financing of the large dams. Various forms of employer management and its effects on the implementation of mass-production projects are discussed in this dialogue. To get the right model of management, the employer and the structure required to deal with the characteristics of large projects over other projects is greatly felt. After looking at the various dimensions of large-scale development projects with an economic role, its investment dimension has been identified as the main axis of choosing the type of employer management. This means that the investor defines and selects the type of executive management to achieve his / her economic goals and capitalization as soon as possible.

It also optimizes the structure and requirements for executing activities according to the needs of the plan, optimizing the structure for necessary coordination, shortening administrative paths, and accelerating it. In the sector of public funds management where the execution capital is provided by this sector, the necessity of transforming this management system from implementation to operation will also be felt and necessary to ensure the conditions of return on capital in a properly structured format $[14,15]$.

\subsection{Risk assessment in mass construction projects}

Risk assessment is one of the key parts of project management in any project. With classical methods such as the risk-probability matrix method, the risk assessment is based only on two main components of the probability of occurrence and the degree of risk effect that may not yield valid results. To this end, it is possible to evaluate strategies for risk assessment in these projects by examining different factors in the occurrence and likelihood 
of risk in a mass project. After identifying the risks in these projects based on their likelihood of occurrence, different risk assessment methods can be mitigated or accepted in mass projects. Accordingly, after reviewing the requirements, strengths, and weaknesses, we can assess and analyze the existing risks to achieve the project objectives.

By identifying the problems and risks that exist in a bulk project, their occurrences and effects are reduced. This is the result of risk management practice that requires a risk assessment to be successful and can minimize cost and impact by using risk assessment and management techniques. Risks to the project. In general, two main approaches to risk management assessment have been estimated:

- Definitive safety assessment

- $\quad$ Probable safety assessment

\section{Materials and methods}

The overall process of risk management consists of two basic parts:

- Identifying, analyzing and modeling risks.

- Allocating risk to project factors and sharing them.

The purpose of this process in the present study is to first provide a unified standard model that balances the interests of all stakeholders and then to identify and develop an allocation mechanism for managing identified risks. According to the process described in the systematic design of the risk management Implementation method, it will be temporarily implemented and tested in social housing projects.

For this purpose, after the necessary training and providing the appropriate context for the team members' on the internal risk management over the implementation methodology and concepts discussed, several meetings will be held following the various stages of the project risk analysis. In these sessions, after evaluating different areas of project risk, origin, the types of risks identified in the most sensitive and important areas of the project will be identified, with the consent of the internal team members from the relevant forms. In the later stages, the @ Risk software will be used to provide an executable model for risk management in the social housing project [16].

\subsection{Initial project risk assessment}

Each organization defines its long-term and short-term goals based on its mission and vision, which has a set of operational plans to achieve them. These programs are potentially associated with threats and opportunities that knowing them can help them achieve their goals and achieve their goals. In fact, in this way, each project is taken from two external perspectives (before entering a project and at the evaluation stage, and related decisions and internal perspectives) after the decision to execute a project and issues related to the implementation of goals and decisions. It is evaluated to identify the scope of issues discussed by team members on the risk identification stage.

But given the abundance of different dimensions affecting the risks of a project and identifying and evaluating more sensitive areas, there is a need to initially evaluate and evaluate different areas of each project using several general indicators in order to be able to Identify the themes or dimensions of a project that need to be examined more thoroughly and carefully. This evaluation is performed to use a general classification of the types of risks in the project and based on two main categories of internal and external risks (RMI.2 and RMI.3) that aim to provide an initial understanding of the dimensions. Every project and asset is the dominant risk in each sector. The values of the projected intervals to be broken down into three categories: high risk, medium risk, and low risk, will be announced by the project risk management team and the risk limits review period $[17,18]$. 


\section{Results}

\subsection{Lala residential complex project in Kabul}

The project of (Lala-560 residential complex project in Kabul), one of the largest social housing projects in the country has been selected as a case study and its data have been analyzed; this project has been carried out in Kabul, Afghanistan. The criteria for selecting this project for the study, its high extent of applicability, the multitude of builders, and the presence of a diverse mix of stakeholders could reflect the overall situation of planning, mass housing construction in Afghanistan and project risk management has considered in this project.

The project of the Lala residential complex in Kabul city with 16 hectares and 560 residential units has implemented since 2014. Land clearance and construction of residential units are in progress at the same time. Housing units are mass-produced by the contractor with the Afghan Ministry of Housing and Urban Development. The cost of construction of this project paid by the government budget and its other part of the applicants of the residential units that are government employees. According to the work plan for all residential units, the project had to be completed by the end of June until the end of December 2016; however, at the time of completion of the residential units, only $59 \%$ of the plans were completed. Infrastructure facilities and other infrastructure were not operational.

The completion rate of the program at the end of 2013 was about $95 \%$, and the completion of the remaining 50 units, which are in various stages of framework and plastering, faces serious challenges such as construction stagnation and rising prices. The following figure (Fig.1) shows the site plan of the Lala Residential Complex Project in Kabul.

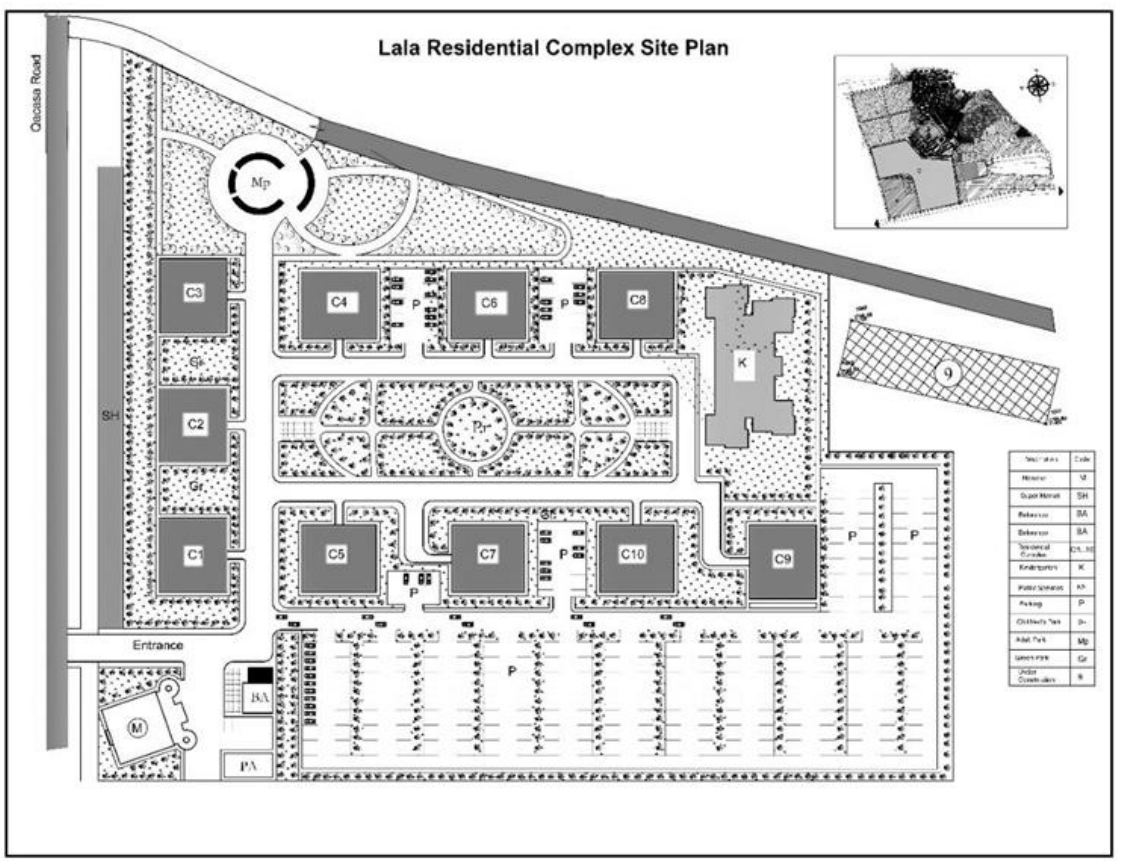

Fig. 1. Lala Residential Complex Site Plan. 


\subsection{Developing interview guidelines and frameworks}

The purpose of this study was to establish the regularity of questions in order to develop a default framework of key themes for examining the status of goals and planning in the management of construction projects (which should be asked about). Subjects selected on the basis of preliminary studies of the research literature as well as the experiences of a second researcher as a preliminary director and senior supervisor of the Ministry of Urban Development and Housing in Kabul in the 560-unit Lala residential project in Kabul (late 2010 to early 2012 and again from the second half of 2013 till now), has been done.

\subsection{Interview methodology}

Interviews were conducted using the "Structured Interviewing" method in which the questionnaire was pre-designed and additional questions were asked from the respondent during the interview. The interviews lasted from 45 to 60 minutes. The questions asked to avoid expressing their perceptions of the interviewee and avoiding the multifaceted and complex questions posed in one question to obtain useful answers. In the end, interviewees were asked to comment if they had any comments about the interview.

\section{Discussion}

The data analysis method used the "Grounded Theory" coding process. This research methodology uses inductive reasoning, in contrast to the hypothetical-deductive model of the scientific method. A study using grounded theory is likely, to begin with, a question, or even just with the collection of qualitative data. While at the same time solidifying the basis of this report in empirical data observations. "Concerning the appropriateness of the present study, the purpose of this study was to discover the underlying aspects affecting the realization of planning objectives in the housing mass sector. Social, without default, encompasses Glazer's methodology, which, in comparison with Strauss and Corbin's (1998) methodology, allows research topics to emerge naturally in the research process, rather than Consider a particular phenomenon or issue from the beginning and before the research begins. In this methodology, data are conceptualized through three stages of open coding, selective coding, and theoretical coding, and ultimately, a fundamental social process and theoretical model that is rooted in the data. 


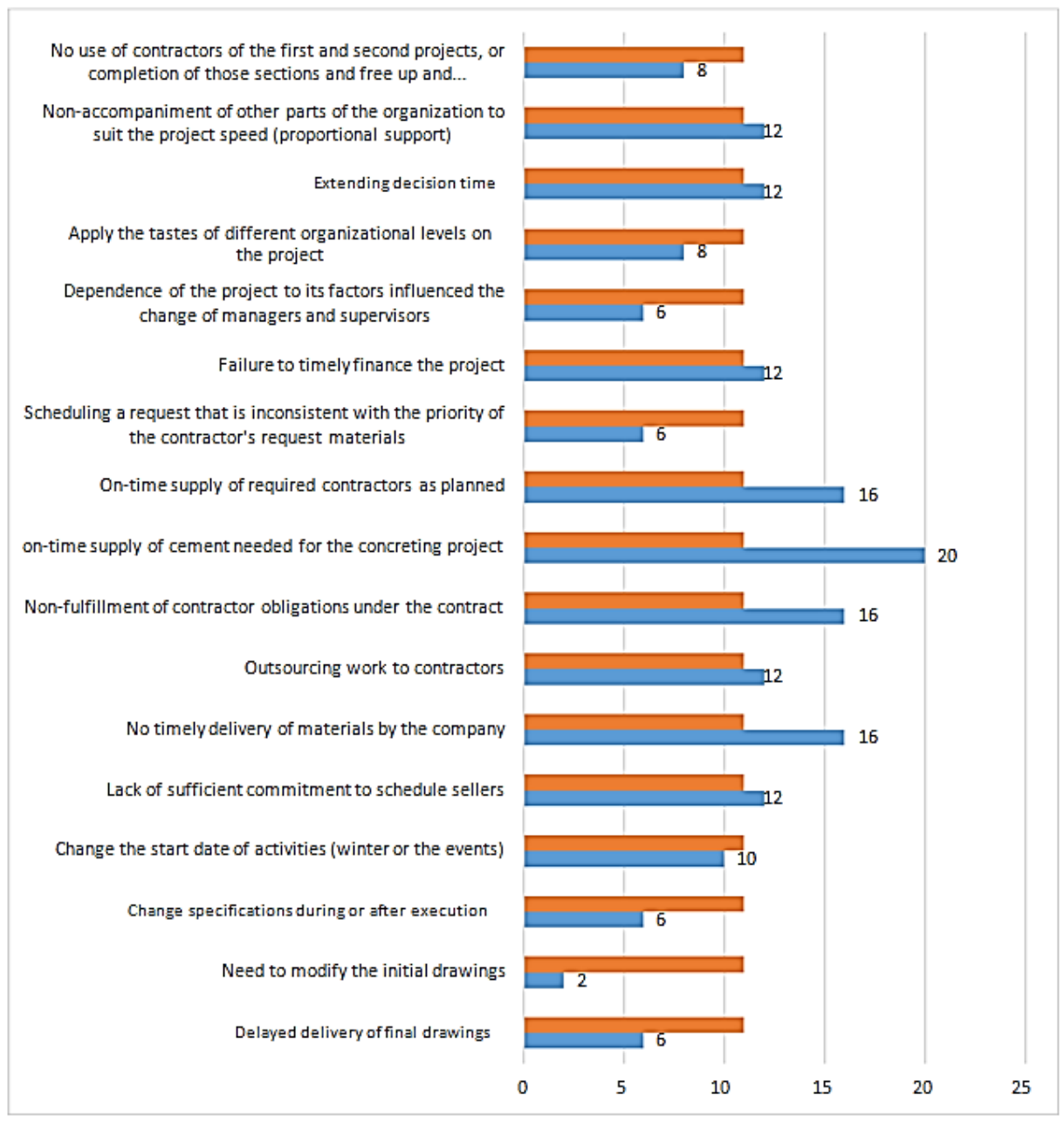

Fig. 2. The results of comparing the value of the risks vs the value of the allowed risks.

This chart (Fig. 2) shows the comparison of the 17 criteria influencing the project risktaking, which is using the analysis performed, shows the results of the risk value compared to the permitted risk value.

\section{Conclusion}

In the past, due to the unknown risk analysis methods, the risk approach has been experimental and experts have considered a certain percentage as unforeseen costs in their estimates. Nowadays, simple methods can be used to evaluate a large part of the unknown risk. Developing a scientific approach to risk management, a comprehensive introduction to the process and applying the method of its application to projects can provide a systematic formulation and application of project risk management in the country as well as its establishment in the construction industry. Risk management is a technique, which used to reduce many costs at the end and make better management decisions.

According to the results of the financial analysis of the risks identified in the project under consideration, the estimated 5\% $(\$ 820,000)$ increase in costs associated with the 
risks identified in the project reflects the catastrophic amount of increased project cost. It should be noted, that the valuation of these risks is only by the initial opinion of the experts and individuals working on the project, and that the risks are only considered during the project construction phase. However, if the other risks of the workshop equipping stage and the contract and the various stages of project construction and operation are considered in the above risk planning, we will be able to achieve a very high-cost estimate and this could Show a serious challenge in discussing the financial costs and risks of social housing projects.

In addition, the above risk analysis was carried out in the early stages with the view that only one project contractor has started and completed the project. While reality shows that the project has not yet reached the operational phase, several contractors have been in the process of implementing the project for four years. With this interpretation, it can be said that the catastrophic number is only a fraction of the lost costs associated with the risks involved in the said social housing project, and the reality of the matter shows a more catastrophic problem.

Finally, after selecting the appropriate response method for each of the highest priority risks, the final step in the process is to allocate the risk of the risk owner or the appropriate person to control the risk factor, in accordance with the principles of risk allocation and commensurate with the capabilities of individuals. As shown on the "RMI.12" form. In this project, based on the sensitivity and compactness of the program, as well as the existence of a variety of risks with a wide range, as well as the organizational constraints on the selection and use of different response methods, monitoring phase time and risk control in the form of "RMI.13" every two months. It was once determined that, following the above implementation process, in accordance with the evaluation of the effectiveness of the reactive methods adopted, as well as changes in the conditions governing the project environment, the internal risk management team should be followed up.

The result from the implementation of the proposed methodology in this research on the risk samples presented shows that the first step to being successful is the involvement and commitment of senior managers and project owners. In other words, what is most important is the decision to identify and mitigate risk by the company executives and transfer it step by step to the project stakeholders. Next, the project executives and stakeholders need to get a proper understanding of how the project will be implemented through proper and timely training. One of the important steps that need to be taken is to create a proper culture throughout the project's organization, providing a space for individuals to be able to influence the implementation process without fear of reproach and accountability for judging the future status of the project. Risk management and its impact on the success of projects focus on continually reviewing the future direction of the project and the challenges and opportunities ahead.

The partial results obtained from the present realization can also be mention as a case study in estimating the financial value of the risk in the "Lala residential project- Kabul".

\section{Reference}

1. H. Aladposh, "Guide to the project management body of knowledge.3rd Edition" (2004).

2. E.S.I. Virginia, I. Arlington, VA. Pritchard, "Risk Management Concepts and Guidance" (2001)

3. Khazaei, A. Abbas, Risk Management Basis for Risk Management in BOT Projects, 4th National Conference on Industrial Engineering (2003), 
4. D. E. Per T. Søren, K. Jørgen, H. V. Trine, Palaeogeography, Palaeoclimatology, Palaeoecologyp, 217-237 (2014). DOI:10.1016/j.tust.2004.01.001.

5. H. Marcel, B. Stuart, L.S. Pau, W. Eddy, Research on Best Practices and Lessons Learnt in Large Infrastructure Projects in Europe (2008).

6. H. Wagner, International Symposium on Underground Excavation and Tunneling (2006).

7. L. Carl, "Risk Management Concepts and Guidance" (2001)

8. Garshab, A. Abbas, Risk Management Basis for Risk Management in BOT Projects, 4th National Conference on Industrial Engineering (2003),

9. B.G. Glaser, International Journal of Qualitative Methods 1(2), 23-83 (2002).

10. R. William, "PMBOK® Guide - Sixth Edition" (2017).

11. Yogaranpan, M, Yoga,Water Technologies Pty. Ltd. Australia, 499-508 (1996).

12. GA. Khouty, International Tunnel and Tunneling 35(2) (2005).

13. B. Li, A. Akintoye, P.J. Edwards, C. Hardcastle, International Journal of Project Management 23(1), 25 - 53 (2005)

14. Abbasnia, Reza, M.S. Wahid "Identification of Critical Risk Assessment and Management of Joint Construction Projects" (2011).

15. A. Kazemi, Kamyar, "Investigating Contractors' Problems and Extending Project Execution Time”(2009).

16. M. Mousavi, Hasan, "Quantitative Study of Delays in National Development Projects" (2009).

17. E.P. Mazob, E.E. Pakhamov, M.G. Belova, "Organization of construction production”, 60 (2006).

18. P.P. Olienik, “Construction organization production”, 576 (2010). 